\title{
Etablering av en gruppe for psykiatrisk epidemiologisk forskning i Bergen
}

\author{
Alv A. Dahl ${ }^{1}$, Ingvar Bjelland ${ }^{2}$, Tor Jacob Moe ${ }^{3}$, Arnstein Mykletun ${ }^{4}$ og Atle Roness ${ }^{5}$ \\ ${ }^{l}$ Klinikk for psykiatri, Aker universitetssykehus HF, Universitetet i Oslo \\ ${ }^{2}$ Seksjon for forebyggende medisin, Institutt for samfunnsmedisin, Universitetet $i$ Bergen \\ ${ }^{3}$ Psykiatrisk klinikk, Haukeland sykehus, Universitetet i Bergen \\ ${ }^{4}$ HEMIL-senteret, Det psykologiske fakultet, Universitetet i Bergen \\ ${ }^{5}$ Psykiatrisk institutt, Universitetet i Bergen
}

Korresponderende forfatter: Professor dr. med. Alv A. Dahl, Klinikk for psykiatri, Aker universitetssykehus HF, Sognsvannsveien 21, 0320 Oslo

Telefon: 22923820 Telefax: 22923971 e-post: a.a.dahl@psykiatri.uio.no

\begin{abstract}
SAMMENDRAG
For å øke bredden av det psykiatriske forskningsmiljøet i Bergen, ble det i 1999 startet en arbeidsgruppe for psykiatrisk epidemiologi. Arbeidsgruppen har 15 medlemmer som alle har pågående prosjekter, og som har møttes regelmessig. Materialet for gruppens arbeid har vært Helseundersøkelsene i Nord-Trøndelag (HUNT-II) og i Hordaland (HUSK). Utfallsvariablene i våre prosjekter har vært angst og depresjon målt ved selvutfyllingtesten Hospital angst og depresjonsskala (HADS). I Bergensgruppen er angst og depresjon undersøkt i forhold til kodimensjonalitetet, fysisk aktivitet, body mass index/hip-waist ratio, global helse, gastrointestinale symptomer, menopause, p-piller, svangerskap og fødsler, søvnplager, røyking, migrene, whiplash, epilepsi, folat-metabolisme, kreft, yrke og helsetjenester. Det ser ut til at vi har dannet grunnlaget for en stabil og produktiv gruppe som sammen med andre grupper kan bidra til et aktivt miljø for psykiatrisk epidemiologi ved Universitetet i Bergen.
\end{abstract}

Dahl AA, Bjelland I, Moe TJ, Mykletun A, Roness A. Establishing a working group for psychiatric epidemiologic research in Bergen. Nor J Epidemiol 2002; 12 (3): 355-360.

\section{ENGLISH SUMMARY}

A working group for psychiatric epidemiology was started at the Department of Psychiatry, Haukeland Hospital, in 1999 in order to expand the fields of psychiatric research at the University of Bergen. The group consists of 15 members, who all have ongoing projects, and who meet regularly. The data for the group has come from the health studies of Nord-Trøndelag (HUNT-II) and Hordaland (HUSK) counties of Norway. The dependent variables of our projects are anxiety and depression that have been self-rated by the Hospital anxiety and depression rating scale (HADS). The Bergen group has investigated anxiety and depression in relation to co-dimensionality, physical activity, body mass index/hip-waist ratio, gastrointestinal symptoms, menopause, anti-conception pills, pregnancies, births, sleep disturbances, smoking, migraine, whiplash, epilepsy, folate metabolism, cancer, occupation, as well as use of health services. The development of the group has been positive and productive, and we hope that collaboration with other groups will contribute to a milieu for psychiatric epidemiology at the University of Bergen.

\section{INNLEDNING}

Det psykiatriske forskningsmiljøet i Bergen hadde lenge hatt sin styrke innen nevrobiologi basert på at mange av psykiaterne hadde tatt sin doktorgrad ved Fysiologisk institutt. Kliniske arbeider hadde særlig vært gjort innen somatiseringslidelser og affektive lidelser og deres behandling. Ingen innen dette miljøet hadde vist større interesse for psykiatrisk epidemiologi. Planleggingen av Helseundersøkelsen i Hordaland (HUSK) skapte en viss endring i dette, og spørsmål om tvangssymptomer, somatisering og suicidalitet ble inkludert fra det psykiatriske miljøet.

IDANT-gruppen (bestående av Alv A. Dahl, Oslo, Marit Bjartveit Krüger og Nils Håvard Dahl, Levanger samt Eystein Stordal, Namsos) hadde allerede analyserettigheter til angst og depresjon i Helseundersøkelsen i Nord-Trøndelag (HUNT-II), kartlagt med Hospital angst- og depresjonsskala (HADS) (1). Siden HUSK skulle kartlegge en rekke andre forhold enn HUNT-II, var det nærliggende å søke om å få med HADS i HUSK også. Etter søknad ble så HADS inkludert i det 
skjemaet som deltakerne i HUSK fikk utdelt ved fremmøte og deretter skulle returnere i posten (skjema 2).

Tor Jacob Moe hadde tiltrådt som avdelingsoverlege ved Psykiatrisk klinikk, Haukeland sykehus i 1997. Han var interessert $i$ at det skulle komme mer forskning knyttet til Psykiatrisk klinikk, og han mente det kunne være naturlig å ta utgangspunkt i at HUSK var underveis. Han drøftet dette med Alv A. Dahl, og de ble enige om at de skulle prøve å etablere en gruppe for psykiatrisk epidemiologisk forskning, som i hovedsak skulle beskjeftige seg med angst og depresjonsdata fra HUSK etter hvert som de ble tilgjengelige. Alv A. Dahl var i den situasjon at han manglet mannskap til å analysere angst- og depresjons-data fra HUNT-II, og han ble enig med Moe om at en gruppe skulle inviteres til å arbeide med data fra HUNT-II inntil HUSK-data forelå.

I 1998/99 gikk det så ut en invitasjon til alle legene på Psykiatrisk klinikk og de ansatte ved Psykiatrisk institutt lokalisert samme sted, om et orienterende møte med sikte på etablering av en studiegruppe for psykiatrisk epidemiologi. Dahl orienterte om HUNT-II, HADS og øvrige variabler som kunne undersøkes med angst og/eller depresjon som avhengige variabler. Det ble gitt anledning til å melde hvilke variabler og problemstillinger en var interessert $i$ å studere. Forutsetningen for å være med i gruppen var en forpliktelse til å skrive minst en artikkel. Datamaskiner og programvare for statistiske analyser forelå fra sykehusets side. Gruppen ble enig om at det trengtes et innføringskurs i statistikk og SPSS, og cand. polit. Arnstein Mykletun ble engasjert til denne oppgaven samt videre datamessig og statistisk veiledning for medlemmene av gruppen. Fra universitetssiden ble professor dr. med. Atle Roness og førsteamanuensis dr. med. Tone Tangen Haug med i gruppen. I samråd med bestyrer Hugo Jørgensen ved Psykiatrisk institutt, ble det bestemt at alle deltakerne i gruppen som ikke hadde disputert, skulle ha en veileder ved Psykiatrisk institutt.

\section{MATERiale OG MEtoder}

Helseundersøkelsen i Hordaland '97-'99 (HUSK) ble utført i 1997-99 i samarbeid mellom Statens helseundersøkelser (SHUS), Universitetet i Bergen og kommunehelsetjenesten i Hordaland. Studiepopulasjonen inkluderte alle individer bosatt i Hordaland født 1953$57(n=29.400)$ i tillegg til 2.291 menn og 2.558 kvinner født 1950-51, og 1.868 menn og 2.470 kvinner født 1925-27 som hadde deltatt $\mathrm{i}$ en tidligere studie $\mathrm{i}$ 1992-93 ("Homocystein-kohorten").

Alle deltakere fikk personlig invitasjon sammen med en informasjonsbrosjyre i posten fra SHUS. Totalt møtte 11.721 menn (61\%) og 13.913 (72\%) kvinner fram til undersøkelsen. Ved fremmøte i undersøkelseslokalet mottok deltakerne samtykkeerklæring og leverte Skjema 1 (selvutfyllende spørreskjema). Videre ble det utført målinger av høyde, vekt, omkrets av hofte og liv, blodtrykk, puls, og ikke-fastende blodprøver for analyser av totalt kolesterol, HDL-kolesterol, triglyserider, kreatinin og glukose. I homocystein-kohorten ble det også gjort analyser av folat, vitamin B12, total homocystein og MTHFR-gen polymorfismen. Deltakerne fikk til slutt med seg Skjema 2 (selvutfyllende spørreskjema) som skulle returneres i posten. Skjema 1 og 2 inkluderte spørsmål om bl.a. egen somatisk og psykisk helse, helsevaner (mosjon, røyking og bruk av kaffe, te og alkohol), bruk av medikamenter, sosioøkonomiske og psykososiale forhold og arbeidsforhold.

Datafilene ble koblet og oppbevart hos SHUS og utsendt til vitenskapelig bruk i desember 2000. HUSK ble tilrådd av Den regionale komité for medisinsk forskningsetikk, helseregion Vest, og godkjent av Datatilsynet.

\section{Måling av angst og depresjon}

I HUSK som i HUNT-II ble angst og depresjon kartlagt med selvutfyllingsinstrumentet Hospital angst- og depresjonsskala (HADS), og for omtale av HADS viser vi til den ledsagende artikkelen.

\section{Resultater}

\section{Etablering av forskningsmiljo for psykiatrisk epidemiologi}

Gruppen konsoliderte seg med 15 medlemmer som hadde valgt emner for prosjekter ut fra variabler $i$ HUNT-II der det ville være interessant å se på angst og depresjon (HADS) som utfallsvariabel. Medlemmene forpliktet seg til å møtes annenhver uke for å diskutere sine prosjekter. Hver fjerde uke kom Alv A. Dahl fra Oslo til møtene og for å gi individuell veiledning. Deltakelsen i møtene har hele tiden vært god, og den vitenskapelige og presentasjonsmessige kvaliteten på fremleggelsene har vært jevnt stigende. Gruppen opprettet en styringsgruppe bestående av Alv A. Dahl, Tone Tangen Haug, Tor Jacob Moe, Arnstein Mykletun, Atle Roness og Ketil Ødegaard for å ta en del økonomiske og strategiske beslutninger ut fra synspunkter i gruppen.

Gruppen søkte og fikk en treårig driftsbevilgning fra Program for mental helse, Norges forskningsråd for å finansiere utviklingen av gruppen, honorering av konsulenttjenester og kjøp av nye analyserettigheter $i$ HUNT-II. To av medlemmene i gruppen, Tone Tangen Haug og Dag Neckelmann bruker prosjektene sine til postdoktor-kvalifisering for professorkompetanse, og Ketil Ødegård og Jan Øystein Berle sikter på doktorgrad for sine prosjekter. Det er mulig at flere i gruppen vil satse på doktorgrad etter hvert.

HUSK ble ledet av professor Grethe S. Tell ved Seksjon for forebyggende medisin, Institutt for samfunnsmedisinske fag, Universitetet i Bergen. Med henne som hovedveileder arbeider Ingvar Bjelland og Bjarte Sanne som doktorgradsstipendiater med data fra HUSK. Bjelland og Sanne er samtidig aktive medlemmer av epidemiologigruppen. 
Ved siden av kontakten med Institutt for forebyggende medisin, har gruppen også etablert et samarbeid med Medisinsk fødselsregister som med konsesjon fra Datatilsynet er blitt koplet mot HUNT-II.

Gruppen har begynt å presentere resultater på kongresser som den amerikanske psykiaterforenings årsmøter, årsmøtene i Nordisk forening for psykiatrisk epidemiologi, og gruppen vil ha en rekke postere på seksjonsmøtet for psykiatrisk epidemiologi i Den europeiske psykiaterforening i april 2002. De første publikasjonene er kommet, en del er i trykken og andre er innsendt til vurdering. Vi viser her til referanselisten.

Besøket til professor Kathleen Merikangas fra Department of Epidemiology, Yale University, senere National Institutes of Health, i april 2001 betydde mye for gruppefølelsen både vitenskapelig og sosialt. Professor Merikangas besøkte også HUNT forskningssenter i Verdal og HUNT-gruppene i Nord-Trøndelag.

\section{Egenskapene til HADS}

Med HADS-testens sentrale betydning for gruppens arbeider, var det naturlig å gi en samlet oversikt over de studier som var gjort med skjemaet. Herrmann hadde publisert en slik oversikt med studier fram til 1996 (2), og det var nødvendig å ta for seg arbeidene som var kommet senere, samt å legge an noen supplerende perspektiver til Herrmann. Bjelland et al. (3) gikk derfor gjennom artikler om HADS publisert fra 1996 til mai 2000. Det dreidde seg om 747 artikler hvorav 71 dreidde seg om psykometri, case-finding og sammenligning med andre tester. Konklusjonen på denne litteraturoversikten var at HADS har en godt etablert tofaktor-struktur som svarer til subskalaen for angst og depresjon. Internkonsistensen av begge subskalaene er god, og en skåre på åtte eller mer viser god sensitivitet og spesifisitet som 'case-finder' for angstlidelser og depresjoner. Korrelasjon med andre vanlig brukte selvutfyllingsmål er også god. Vi kan derfor konkludere med at HADS er en mye brukt og godt validert selvutfyllingstest for angst og depresjon med gode psykometriske egenskaper.

\section{Kodimensjonalitet av angst og depresjon}

'Komorbiditets-kameratene' er en gruppe som har interessert seg særlig for sammenhengen mellom angst og depresjon (Ingvar Bjelland, Alv A. Dahl, Arnstein Mykletun og Eystein Stordal). Oppmerksomheten rundt komorbiditet mellom angst og depresjon har vært stor de siste 10-15 årene. Studiene bygger imidlertid i hovedsak på et kategorisk perspektiv på psykiske lidelser, hvor tilstandene karakteriseres som enten til stede eller fraværende. Stadig flere studier bekrefter at angst og depresjon er spektrumslidelser, det vil si at tilstanden finnes $i$ alle grader fra ingen symptomer til ekstremt invalidiserende lidelse. I den foreliggende studien har vi derfor sett på forholdet mellom angst og depresjon ut fra et dimensjonalt perspektiv.
Vi relaterte HADS-A og -D delskala skårer fra HUNT-II til hverandre på ulike måter, både som helhet og stratifisert på kjønn og 10-års aldersgrupper. Vi fant at forholdet mellom angst- og depresjonssymptomer hos enkeltindivider i gjennomsnitt var dominert av angst $i$ omtrent alle alders- og kjønnsstrata, men mest hos kvinner og i yngre aldersgrupper. "Rene" tilstander (uten vesentlig innblanding av den andre komponenten) av angst og depresjon var relativt uvanlige. Ved "klinisk nivå" av angst fantes alle grader av innblanding av depresjon (og omvendt). Det var en lineær sammenheng mellom angst og depresjon med økende symptomgrad gjennom hele HADS-skalaen. Studien er innsendt for publikasjon (4).

\section{Angst, depresjon og fysisk aktivitet}

Lege Erlend Bergesen har studert sammenhengen mellom fysisk aktivitet og angst og depresjon, og finner at fysisk inaktive rapporterer depresjon og noe oftere angst enn fysisk aktive. Disse sammenhenge skyldes ikke alder, kjønn eller arbeidsrelatert fysisk aktivitet. Assosiasjonen mellom moderat fysisk aktivitet og fravær av depresjon og angst er sterkere enn for hard aktivitet. Frekvensen av aktivitet ser ikke ut til å ha særlig betydning.

\section{Angst, depresjon og BMI/HWR}

Overlege Ann-Christin Rivenes har unders $ø$ kt body mass index (BMI) og waist-hip-ratio (WHR) i HUNTII for å teste hypotesen om overvekt og abdominell fedme er assosiert med prevalensen av angst og depresjon. Regresjonsanalyser med kontroll for demografi, relasjoner, somatisk sykdom og livsstil, viste bare en moderat reduksjon i prevalensen for angstlidelser hos menn og kvinner med økt BMI, noe som var statistisk signifikant.

\section{Angst, depresjon og gastrointestinale symptomer}

HUNT har fire spørsmål om gastrointestinale plager: kvalme, halsbrann, diare og obstipasjon. Disse plagene er blitt relatert til angst og depresjon av førsteamanuensis dr. med. Tone Tangen Haug. Førtiătte prosent rapporterte minst en gastrointestinal plage i løpet av det siste året. Angstlidelser ble funnet hos $15,3 \%$ og depresjon hos $10,4 \%$. Angst var den viktigste risikofaktor for kvalme (OR 3,42). Depresjon var også en risikofaktor, men mindre enn angst. Angst og depresjon var også assosiert med halsbrann, diare og obstipasjon, men svakere enn med kvalme. Verken demografiske faktorer, livsstilsfaktorer eller andre somatiske plager kunne forklare assosiasjonen mellom angstdepresjon og gastrointestinale plager. To arbeider om disse funnene er publisert $(5,6)$.

\section{Angst, depresjon og kvinnedata (menopause, p-piller)}

Førsteamanuensis dr. med. Tone Tangen Haug undersøkte angst og depresjon vurdert i forhold til menstru- 
asjonsstatus. Det var signifikant høyere skåre på depresjon i den perimenopausale alder (48-53 år) i forhold til premenopausal alder. Det var også en signifikant høyere skåre på depresjon i postmenopausal alder i forhold til premenopausal alder, mens det ikke var noe signifikant forskjell i skåre på depresjon mellom perimenopausal alder og postmenopausal alder. For angstskåre var det ingen signifikante forskjeller relatert til menstruasjonsstaus. Disse funnene er under utskrivning.

\section{Angst, depresjon og sovnplager}

Assistentlege dr. med. Dag Neckelmann har undersøkt samvariasjon mellom søvnforstyrrelser og depresjonsog angstsymptomer. Ved å sammenholde data fra HUNT-I og HUNT-II er det funnet at langvarige søvnvansker er assosiert med utvikling av angstsymptomer, men at langvarige søvnvansker ikke er sterkere assosiert til depressive symptomer enn kortvarige søvnvansker. Det langsiktig prospektive aspektet i denne studien illustrerer en stor styrke i HUNT-studien. Artikkel om dette er innsendt (7). Utarbeidelse av et arbeid om årstidsvariasjon i forekomst av søvnvansker i relasjon til angst og depresjon pågår.

\section{Angst, depresjon og forbruk av helsetjenester}

Professor dr. med. Atle Roness har ønsket å undersøke i hvilken grad mennesker med angst, depresjon og komorbid angst og depresjon søker hjelp for sine plager. Data fra HUNT-II er benyttet. Av de som har "ren angstlidelse" (uten depresjon) er det ca. 1/4 som noensinne har søkt hjelp. Av de som har "ren depresjon" (uten angstlidelse) har omtrent en av ti søkt hjelp, mens av de som både har angst og depresjon har nærmere halvparten søkt hjelp. Dette viser seg at jo høyere man skårer på henholdsvis angst og depresjon, jo hyppigere har man søkt hjelp.

Det er undersøkt hvordan hjelpsøkingen for mennesker med angst, depresjon og komorbid lidelse fordeler seg på følgende faktorer: kjønn, alder, utdannelse, urbanitet (by/land), sosialt nettverk, og kontakt med lege siste år. Det mest oppsiktsmessige funnet er at deprimerte i så liten grad kommer til behandling, men også de med angst har relativt sjelden søkt hjelp. Dersom man både har angst og depresjon, er hjelpsøking hyppigere. Funnene er under utskrivning.

\section{Angst, depresjon og royking}

Ass.lege Vigdis Elin Giæver Syrstad studerer i HUNTII sammenhengen mellom røyking og nåværende symptomer på angst og depresjon, samt om antall sigaretter røykt daglig gjorde noen forskjell. Tidligere studier har vist en sammenheng mellom røyking og psykiske lidelser. Det ble funnet en sammenheng mellom angst og depresjon selv etter kontroll for alder, kjønn og henholdsvis angst og depresjon. Vi finner en umiddelbar økning i forekomst av angst fra null til en sigarett, mens økningen i depresjon kommer noe senere, med økning i antallet sigaretter røykt daglig.

\section{Angst, depresjon og subjektiv helse}

Konst. overlege Øystein Elgen undersøker forholdet mellom pasienters beskrivelse av egen helse og deres score for angst og depresjon. Tilsvarende gjøres også for pasientenes subjektive helse og score for ulike somatiske lidelser. Hypoteser som skal testes er: 1) Generell, subjektiv helse er i større grad uttrykk for psykisk helse enn for somatisk helse. 2) Psykisk helse påvirker sammenhengen mellom fysisk og generell helse. Elgen vil søke doktorgrad for dette prosjektet samt et prosjekt om sammenhengen mellom religiøs tilhørighet og engasjement med ulike mål på psykisk, psykosomatisk og somatisk helse innenfor helseundersøkelsen i Oslo (HUBRO 2001).

\section{Angst, depresjon og whiplash}

Overlege Hanne Gro Wenzel har undersøkt sammenhengen mellom selvrapportert nakkeslengskade i HUNT II og angst og depresjon. Det ble funnet en positiv sammenheng, men bare for skader som hadde skjedd for mer enn to år siden. En del av dette kan forklares med langvarige smerter som følge av skaden. I øvrig drøftes to ulike forklaringer, hhv. "hukommelsesbias" og "attribusjonshypotese" som forklaring på funnene. Artikkelen om dette er i trykken (8).

\section{Angst, depresjon og migrene}

Lege Ketil Ødegård har arbeidet med dette sammen med førsteamanuensis dr. med. Ole Bernt Fasmer, UiB og førsteamanuensis dr. med. John-Anker Zwart, NTNU. 49205 personer svarte på spørsmålene om migrenehodepine og angst og depresjon målt med HADS i HUNT-II. Det var en signifikant økt risiko for depresjon og angstlidelser (HADS-A/HADS-D $\geq 8$ ) hos personer med migrene både med og uten aura, hos begge kjønn. Risikoen for depresjon (OR 1,85 hos menn og OR 1,40 hos kvinner) og angstlidelser (OR 2,15 hos menn og OR 1,65 hos kvinner) var lavere hos kvinner med migrene uten aura, sammenlignet med menn med migrene uten aura. Når det gjelder migrene med aura, finner man ingen signifikant forskjell mellom kjønnene verken ved angst eller depresjon. Når man korrigerer for effekten av angst og depresjon respektivt, finner man at det er mengden av angstsymptomer som bestemmer forekomsten av migrene. Depressive symptomer alene har ingen innvirkning på forekomsten av migrene.

\section{Angst og depresjon ved svangerskap og fodsler}

Stipendiat Jan Øystein Berle har fått tilgang til data fra HUNT-II knyttet til svangerskap og barnefødsel og forekomst av angst og depresjon. Preliminære data viser ingen økt prevalens av angst og depresjon hos kvinner i året etter barnefødsel sammenlignet med 
andre livsperioder. Arbeidet videreutvikles og vil bli publisert i artikkelform.

Berle tok for et år siden initiativ til å etablere et samarbeid med Medisinsk fødselsregister i Bergen som nå er i god gjenge. Søknad til Datatilsynet samt rettighetshavere om kobling av HUNT-II data og Medisinsk fødselsregister for flere delprosjekter ble akseptert i løpet av 2001. Det første delprosjektet, en prospektiv studie for å teste hypoteser om at angst og depresjon hos kvinner i svangerskapet er assosiert med lav fødselsvekt, for tidlig fødsel og fødselskomplikasjoner hos deres barn, er under arbeid. Det ventes resultater i løpet av våren 2002. Samarbeidet som er etablert med Medisinsk fødselsregister anses som spesielt verdifullt, da registeret er verdens eldste landsdekkende fødselsregister.

\section{Angst, depresjon og epilepsi}

Epilepsi er en sykdom som kan få store konsekvenser for dem som er rammet med hensyn på både yrkesvalg og fritidsaktiviteter. Det antas å være en overhyppighet av angst og depresjon blant epilepsipasienter. Gjennom et samarbeid med leger ved Nevrologisk avdeling, St. Olavs Hospital, NTNU vil ass.lege Erik R. Hauge etterprøve dette ved å se på angst, depresjon og epilepsi i HUNT-materialet. Mens mange tidligere undersøkelser er sykehusbaserte, representerer HUNT en annen innfallsvinkel som kan gi mer relevante data om epilepsipopulasjonen.

\section{Angst, depresjon og kreft}

Psykolog og cand. polit. Arnstein Mykletun har nylig startet på sitt doktorgradsprosjekt hvor noen av arbeidene skal dreie seg om betydningen av angst og depresjon og kreft. I dette prosjektet er det innledet et samarbeid med professor dr. med. Sophie D. Fosså og stipendiat Carina Nord, ved Det norske radiumhospital. Dette forskningsmiljøet har allerede brukt HADS i flere arbeider (9). Hypotesene som Mykletun skal teste er: (1) Gir angst og depresjon en økning i risikoen for senere kreft, og (2) Vil det pre- og komorbide nivået av angst og depresjon påvirke prognosen for kreft. Disse spørsmålene er uavklart i litteraturen, og hypotesene vil bli testet på et datamateriale hvor HUNT-II er koblet til Kreftregisteret. Tilsvarende analyser kan utføres med utgangspunkt i HUNT-I som ble gjennomført i Nord-Trøndelag i 1984-86, men spørsmålene som tapper angst og depresjon i HUNT-I er få og ikke validerte.

\section{Angst, depresjon og yrke}

Forskningstipendiat Bjarte Sanne arbeider med angst og depresjon i relasjon til yrke med HUSK-data, som en del av sitt doktorarbeid. Angst og depresjon forårsaker et stort og økende sykefravær, samtidig med at omstillingene $\mathrm{i}$ arbeidslivet akselererer. Uheldige arbeidsforhold kan bidra til utvikling av angst og depresjon. Som ledd i identifiseringen av angst- og depresjonsframkallende faktorer i arbeidslivet, undersøkes 18990 individer i 40-årene fra HUSK-undersøkelsen i forhold til sammenhengen mellom yrkes- og næringsklassifisering og HADS-skåre. Materialet stratifiseres på kjønn, grunnet ulik fordeling av angst og depresjon samt yrke mellom kjønnene. Foreløpige analyser viser at grupper med lav utdanning og formell kompetanse har forhøyet angst- og depresjonsnivå. Yrkesgruppene som kommer dårligst ut er bønder og fiskere. Mulige årsaker blir diskutert ut fra sentrale stress- og burnout-teorier.

\section{Angst, depresjon og faktorer knyttet til folatstoffskiftet}

Dette arbeidet blir utført av NFR-stipendiat Ingvar Bjelland i samarbeid med Grethe S. Tell, Stein E. Vollset, Helga Refsum og Per M. Ueland. Studier har vist en sammenheng mellom folatmangel og depresjon. Betydningen av homocystein, vitamin B12 og C677T metylentetrahydrofolat reduktase polymorfismen (MTHFR-677C->T) er derimot lite undersøkt. Angst, som ofte forekommer sammen med depresjon, har ikke blitt inkludert $\mathrm{i}$ disse studiene. Logistiske regresjonsanalyser ble utført på ca. 5000 individer $i$ Homocysteinkohorten i HUSK som hadde HADS skårer (utfallsvariabler) og resultater på folat, homocystein, vitamin B12 og MTHFR polymorfismen (forklaringsvariabler). Både MTHFR TT-genotypen og homocystein var signifikant assosiert med depresjon, men ikke angst. Verken folat eller vitamin B12 var assosiert med depresjon eller angst. MTHFR TT genotypen og hyperhomocysteinemi ser ut til å være risikofaktorer for depresjon.

\section{KONKLUSJON}

Etter tre års virksomhet synes gruppen for psykiatrisk epidemiologi i Bergen å ha konsolidert seg. Alle deltakerne er i gang med prosjekter, og noen er allerede ført fram til publikasjon. Det synes som om gruppen har funnet en konstruktiv arbeidsform, og den har knyttet kontakter med andre forskergrupper lokalt og internasjonalt. Det har vært god aktivitet i forhold til presentasjoner på internasjonale kongresser. Gruppen har i det vesentlige arbeidet med data fra HUNT-II, men to av deltakerne har konsentrert seg om data fra HUSK. Det er å ønske at denne databasen blir mer utnyttet $\mathrm{i}$ gruppens videre arbeid. Angivelig er analysene av andre psykiatridata i HUSK kommet i gang. I tillegg er det barne- og ungdomspsykiatriske miljøet i Bergen i ferd med å starte en større epidemiologisk undersøkelse av barn i alderen 7-9 år ("Barn i Bergen"). Dette lover godt for å få et levende og aktivt miljø for psykiatrisk epidemiologi ved Universitetet $i$ Bergen videre framover. 


\section{REFERANSER}

1. Zigmond AS, Snaith RP. The hospital anxiety and depression scale. Acta Psychiatr Scand 1983; 67: 35-41.

2. Herrmann C. International experiences with the Hospital anxiety and depression scale - a review of validation data and clinical results. J Psychosom Res 1997; 42: 17-41.

3. Bjelland I, Dahl AA, Tangen Haugen T, Neckelmann D. The validity of the Hospital Anxiety and Depression scale. An updated literature review. J Psychosom Res 2002; 52: 69-77.

4. Bjelland I, Stordal E, Mykletun A, Dahl AA. Co-dimensionality of anxiety and depression in a large population (under innsendelse 2002).

5. Tangen Haug T, Mykletun A, Dahl AA. The prevalence of nausea in the community: psychological, social and somatic factors. Gen Hosp Psychiat 2002; 24: 81-86.

6. Tangen Haug T, Mykletun A, Dahl AA. Is anxiety and depression related to gastrointestinal symptoms in the general population? Scand J Gastroenterol 2002; 37: 294-298.

7. Neckelmann D, Myklertun A, Dahl AA. Chronic insomnia as a risk factor for development of anxiety but not for depression. Am J Psychiatry (innsendt 2002).

8. Wenzel HG, Haug TT, Mykletun A, Dahl AA. A population study of anxiety and depression among persons who report whiplash traumas. J Psychosomat Res (i trykk 2002).

9. Fosså SD, Dahl AA. Short Form 36 and Hospital anxiety and depression scale: a comparison based on patients with testicular cancer. J Psychosomat Res 2002; 52: 79-87. 